\title{
A study of histological changes of human placenta in rural population of eastern India
}

\author{
Mrinal Kanti Karmakar', Sambit Kar ${ }^{2 *}$, S. M. Kumar ${ }^{3}$, Subir Kumar Chattopadhyay ${ }^{3}$, \\ L. K. Vaid ${ }^{4}$, Sukanta Sen
}

\begin{abstract}
${ }^{1}$ Department of Anatomy, ${ }^{2}$ Department of Obstetrics and Gynecology, ICARE Institute of Medical Sciences and Research, Haldia, West Bengal, India

${ }^{3}$ Department of Anatomy, Mata Gujri Memorial Medical College and LSK Hospital, Kishanganj, Bihar, India

${ }^{4}$ Department of Anatomy, Jagannath Gupta Institute of Medical Sciences and Hospital, Kolkata, West Bengal, India

${ }^{5}$ Department of Pharmacology, ICARE Institute of Medical Sciences and Research, Haldia, West Bengal, India
\end{abstract}

Received: 02 June 2018

Accepted: 03 July 2018

\section{*Correspondence:}

Dr. Sambit Kar,

E-mail: sambitspidy@gmail.com

Copyright: (C) the author(s), publisher and licensee Medip Academy. This is an open-access article distributed under the terms of the Creative Commons Attribution Non-Commercial License, which permits unrestricted non-commercial use, distribution, and reproduction in any medium, provided the original work is properly cited.

\begin{abstract}
Background: Placenta is essential for maintenance of pregnancy and for promoting normal growth and development of fetus. It forms the morphological record of anatomical condition, intrauterine events and intrapartum events of gestation. Present study has been undertaken to record the data on the morphology and histology of placenta from mothers with hypertension and diabetes.

Methods: This study showed several significant morphological and histological differences in the placenta of the mother with GDM and hypertensive placenta. The histological study of the placenta was done under microscope and number of syncytial knots, cytotrophoblastic cellular proliferation, fibrinoid necrosis, endothelial proliferation, calcified and hyalinised villous spots were noted per low power field in the diabetics and hypertensive group in comparison to control group.

Results: All other parameters including area, thickness, diameter, and circumference of GDM placenta show a significant increase when compared with normal placenta. The gross anatomic features of placentae e.g infarcted areas, calcified areas and marginal insertion of the umbilical cord in the study group show significant increase in value $(p>0.01)$ in diabetic and hypertensive groups when compared to that of the control or normal group.

Conclusions: In present study we found that hypertensive placentae tend to be slightly smaller in size, weight, volume, area, thickness, diameter, circumference and feto-placental ratio than normal placentae but the parameters were found to be significantly greater than that of normal placentae in case of diabetic placentae. No significant differences were found in umbilical cord insertion. In normal pregnancy cases we found several histological findings which were increased in hypertensive and diabetic cases.
\end{abstract}

Keywords: Diabetes mellitus, Histology, Morphology, Placenta, Pathology, Pregnancy induced hypertension

\section{INTRODUCTION}

The human placenta is an intrauterine fusion of fetal and maternal tissues for the purpose of physiological transfer of nutrients and oxygen from mother to fetus and transfer of waste products of metabolism from fetus to mother for continuation of fetal life. Placenta is the vital organ for maintaining pregnancy and promoting development of the fetus. The intrauterine existence of fetus is dependent on this vital organ. ${ }^{1}$ Placenta is the mirror of maternal and fetal status. Hypertensive disorders in pregnancy like 
pregnancy induced hypertension (PIH); preeclampsia; eclampsia; or chronic hypertension aggravated by pregnancy leads to intrauterine growth restriction (IUGR) of fetus, fetal distress or even intrauterine death due to compromised utero-placental blood flow. ${ }^{2,3}$

In normal pregnancy the cytrotrophoblastic invasion into the spiral arteries of intervillous spaces occur in a retrograde fashion deep into the myometrium, the muscular and elastic tissue coats of arteries and these are replaced by fibrinoid substances which lead to funneling and dilatation of spiral arteries thus increasing the uteroplacental blood flow Brosens et al. ${ }^{4}$ However these changes are confined to the decidua only in patients having pre-eclampsia and IUGR which results in varying grades of placental ischemia Grannum PA. ${ }^{5}$

Pregnancy is also diabetogenic state by virtue of various physiological changes which causes insulin resistance. During normal pregnancy despite increase in plasma levels of insulin, there occurs decreased glucose tolerance by third trimester.

Mothers at risk are those who have positive family of diabetes, history of previous stillborn or previous large baby and polyhydromnios. In gestational diabetes usually, there is delivery of large babies and large placentas. The mother also has high risk of hypertensive disorder, abortion, stillbirth, preterm labour, puerperal sepsis etc. ${ }^{6}$

Diabetic mother's placenta is larger in size, pale appearing due to villous edema and it may also have some histological changes commonly found in PIH as diabetes is associated with maternal hypertension too. Neonatal complications like hypoglycemia, respiratory distress syndrome, hyperbilirubinaemia etc may be also found in these causes. $6,7,8$

In conclusion it will be of great clinical importance since if the variations in dimensions such as weight, volume, thickness, diameter and area of placentas are studied along with the birth weight, birth length of babies and neonatal complications if any and a relation established between the placental and fetal parameters. This study will serve greatly the interest of both the mother and her baby.

The information gathered by this study will certainly help obstetricians and pediatricians to take further precautions before, during, and after labour to modify the course of pregnancy as well as the perinatal outcome. The aim and objective of the present study was to study of relevant morphology and histopathological changes in normal, hypertensive and diabetic placenta.

\section{METHODS}

After acquiring local ethical approval and informed patient consent, the materials of the present study i.e. placentae were collected at random from pregnancy cases attending the department of Obstetrics and Gynaecology at MGM medical college and LSK Hospital.Kishanganj. Bihar, during the period from Jan-2012 to Dec-2012.

\section{Selection of cases}

A total number of 150 cases were included in this study. All the cases included in this study were booked cases. In each case antenatal check up was done routinely. The cases were then divided into three main groups.

- Pregnancy cases without any complication or $=50$

- Normal pregnancy

- $\quad$ Pregnancy cases with PIH = 50

- Pregnancy cases with gestational diabetes $=50$

Each group comprised of patients having known LMP (last menstrual period), EDD (Expected date of delivery), blood pressure, blood sugar levels and gestational period ranging from 36 to 40 weeks. In each case antenatal record having patient's name, identification, age, parity, height and weight was recorded.

\section{Method of the Study}

Clinical studies were done during pregnancy as well as in labour and post-partum period. At labour room placentae were collected as fresh specimen after delivery and then examination was carried out in the following way by morphological and histological. In some cases, few sections of placentae were kept in $10 \%$ buffered formal saline (initial fixation). These specimens were sent to histopathology laboratory for preparing slides. The slides then examined microscopically.

\section{Histology of placenta}

After external examination was done, multiple sections of placenta were taken by cutting it at an interval of $3 \mathrm{~cm}$. These cut sections were examined for the presence of infracts, calcification, intervillous thrombosis and cysts. Some of the cut sections were selected and kept for histological examination and fixed in $10 \%$ formal saline solution.

The cut sections were again cut in small pieces of $5 \mathrm{~mm} \mathrm{x}$ $3 \mathrm{~mm} \times 2 \mathrm{~mm}$. These pieces were kept in running water overnight for better fixation. Then dehydration of the fixed tissues was done by dipping them serially in increasing strength of alcohol i.e. $70 \%, 90 \%$ and absolute alcohol for 24 hours and 1 hour respectively. In absolute alcohol 3 changes were to be given each last for 1 hour.

Then tissues were treated with xyline as the dealcoholising agent $1 / 2$ an hour each change. The translucency is used as a guide to indicate dealcoholinisation. Then the tissues were kept overnight in a paraffin pot at $58^{\circ} \mathrm{C}$ to $60^{\circ} \mathrm{C}$, then 2 nd change in paraffin is given for 1 hour. Blocks were then made from 
which sections were cut at 5-micron thickness using a rotary microtome. These were fixed a clean glass slides by albumin. The slides were dipped in hot water bath, dried and again placed on a hot plate. After melting of wax the slides were removed from hot plate and then stained.

\section{The method of staining of slides}

De-paraffinized the section and treat the section with xylene. Immediately after taking it out from the drying oven / hot plate, repeat xyline treatment with agitation (3 to 4 minutes in each) was done.

Then take the section to water through downgraded alcohol bath (100\% - 90\% - 70\%) for 30 to 60 second in each and wash in tape water, rinse in distilled water drain well. Stain with Harri's haematoxylin solution for 3 to 5 minutes was done and then wash it in running tap water. Quickly dip slides in and out of $0.5 \%$ hydrochloric acid and then wash briefly for 30 to 60 seconds. Then dip several times in dilute ammonia water. After that the section was changed to a blue color. Then wash in water and rinse in $95 \%$ alcohol.

After that agitate it in eosin staining solution for 10 to 60 seconds and placed it in $70 \%$ alcohol (30 to 60 seconds). Finally, clear in xyline ( 2 changes 30 to 60 seconds in each) and allow the excess xyline to drain out and mount Canada balsam with a cover slip.

\section{RESULTS}

Table 2: Placental morphometry in case of normal uncomplicated pregnancies along with birth weight and fetoplacental ratio.

\begin{tabular}{|c|c|c|c|c|}
\hline $\begin{array}{l}\text { Total no. of normal } \\
\text { pregnancies }\end{array}$ & Placental parameters & Maximum & Minimum & Average \\
\hline \multirow[t]{8}{*}{ 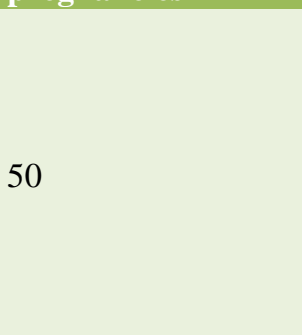 } & Placental weight (gm) & 570 & 340 & 510.1 \\
\hline & Placental volume $(\mathrm{cc})$ & 515 & 300 & 431.84 \\
\hline & Placental area (sq.cm) & 211.2 & 112.2 & 183.65 \\
\hline & Placental thickness $(\mathrm{cm})$ & 2.2 & 0.9 & 1.68 \\
\hline & Placental diameter $(\mathrm{cm})$ & 17.6 & 12 & 15.44 \\
\hline & Placental circumference $(\mathrm{cm})$ & 55.4 & 37 & 48.36 \\
\hline & Birth weight of baby (kg) & 3 & 1.7 & 2.58 \\
\hline & Feto-placental ratio & 5.76 & 4.76 & 5.07 \\
\hline
\end{tabular}

Table 3: Number of cases in each group with percentages in relation to insertion of umbilical cord on the fetal surface.

\begin{tabular}{|lllll|}
\hline No. of cases in group & $\begin{array}{l}\text { Central type } \\
\text { 76-100\% }\end{array}$ & $\begin{array}{l}\text { Eccentric type } \\
\text { Medial type } \\
\mathbf{5 1 - 7 5 \%}\end{array}$ & $\begin{array}{l}\text { Lateral type } \\
\mathbf{2 6 - 5 0 \%}\end{array}$ & $\begin{array}{l}\text { Marginal type } \\
\mathbf{0 - 2 5 \%}\end{array}$ \\
\hline Normal 50 cases & $15(30 \%)$ & $16(32 \%)$ & $3(6 \%)$ & $16(32 \%)$ \\
\hline Hypertensive 50 cases & $16(32 \%)$ & $13(26 \%)$ & $2(4 \%)$ & $19(38 \%)$ \\
\hline Diabetic 50 cases & $10(20 \%)$ & $20(40 \%)$ & $5(10 \%)$ & $15(30 \%)$ \\
\hline Total =150 cases & $41(27.33 \%)$ & $49(32.66 \%)$ & $10(6.66 \%)$ & $50(33.33 \%)$ \\
\hline
\end{tabular}


The Table 2 shows average placental weight, placental volume and placental diameter in normal uncomplicated pregnancies was $510.1 \mathrm{gms}, 431.84 \mathrm{cc}$ and $15.44 \mathrm{~cm}$ respectively.

The Table 3 shows insertion of umbilical cord on the fetal surface was noted central type in normal pregnancy, hypertensive and diabetic cases with pregnancy by 15 (30\%),16 (32\%) and $10(20 \%)$ respectively.
A total of $41(27.33 \%)$ was noted as central type insertion of umbilical cord on the fetal surface.

All other parameters including area, thickness, diameter, and circumference of GDM placenta show a significant increase when compared with normal placenta in Table 4.

Table 4: Comparison between normal, diabetic and hypertensive cases.

\begin{tabular}{|llllll|}
\hline Placental parameters & Normal cases & Hypertensive cases & Diabetic cases & P-value & Comments \\
\hline Placental weight $(\mathrm{gm})$ & 510.1 & 493.18 & 577.9 & $<0.001$ & HS \\
\hline Placental volume $(\mathrm{cc})$ & 431.84 & 406.8 & 494.1 & $<0.001$ & HS \\
\hline Placental area $(\mathrm{sq}$ cm) & 183.65 & 179.54 & 219.3 & $<0.003$ & HS \\
\hline Placental thickness $(\mathrm{cm})$ & 1.68 & 1.54 & 2.32 & $<0.001$ & HS \\
\hline Placental diameter $(\mathrm{cm})$ & 15.44 & 15.08 & 16.74 & $<0.018$ & HS \\
\hline Placental circumference $(\mathrm{cm})$ & 48.36 & 46.58 & 52.06 & $<0.019$ & HS \\
\hline Birth weight of baby $(\mathrm{kg})$ & 2.58 & 2.37 & 3.44 & $<0.001$ & HS \\
\hline Feto-placental ratio & 5.07 & 4.82 & 5.96 & $<0.001$ & HS \\
\hline
\end{tabular}

Table 5: Comparison of perinatal outcome in normal, hypertensive and diabetic mothers.

\begin{tabular}{|llll|}
\hline $\begin{array}{l}\text { Perinatal } \\
\text { outcome }\end{array}$ & $\begin{array}{l}\text { Normal } \\
\text { cases }\end{array}$ & $\begin{array}{l}\text { Hypertensive } \\
\text { cases }\end{array}$ & $\begin{array}{l}\text { Diabetic } \\
\text { cases }\end{array}$ \\
\hline Live birth & 50 & 48 & 46 \\
\hline Term & 45 & 45 & 40 \\
\hline Pre-term & 05 & 03 & 06 \\
\hline $\begin{array}{l}\text { Still birth } \\
\text { Term }\end{array}$ & - & 02 & 04 \\
\hline Pre-term & & - & 01 \\
\hline $\begin{array}{l}\text { Early } \\
\text { neonatal } \\
\text { death }\end{array}$ & - & 02 & 03 \\
\hline Term & & $\begin{array}{l}\text { birth } \\
\text { asphyxia) }\end{array}$ & MAS.) \\
\hline Pre-term & & 02 & 02 \\
\hline & $\begin{array}{l}\text { Total=50 } \\
\text { cases }\end{array}$ & $\begin{array}{l}\text { Total=50 } \\
\text { cases }\end{array}$ & $\begin{array}{l}\text { Total=50 } \\
\text { cases }\end{array}$ \\
\hline
\end{tabular}

The Table 5 shows majority of perinatal outcome was term and live deliveries of babies. Early neonatal death was observed two cases each in hypertensive and diabetic group associated with pregnancy.

The gross anatomic features of placentae e.g. infarcted areas, calcified areas and marginal insertion of the umbilical cord in the study group show significant increase in value $(\mathrm{p}>0.01)$ in diabetic and hypertensive groups when compared to that of the control or normal group (Table 6).

Table 7 shows that common histological findings syncitial knots formation, cytotrophoblastic cellular proliferation and hyalinization of villi was noted $22 \%$, $10 \%$ and $12 \%$ in pregnancy with hypertension. Similar pattern was also observed in diabetic group.

The important microscopic findings are depicted in Figure 7 of diabetic placenta showed increased syncytial knots, fibrinoid necrosis, decreased VSM, and chorangiosis.

Table 6: Comparison of gross morphological changes in placental in mothers of different age group.

\begin{tabular}{|lllll|}
\hline Groups & $\begin{array}{l}\text { Average no. of } \\
\text { cotyledons }\end{array}$ & $\begin{array}{l}\text { Average no. of } \\
\text { infracted areas }\end{array}$ & $\begin{array}{l}\text { Average no. of } \\
\text { calcified regions }\end{array}$ & $\begin{array}{l}\text { Presence of } \\
\text { hemorrhage }\end{array}$ \\
\hline Normal $[\mathrm{n}=50]$ & 16 & 03 & 05 & 03 \\
\hline Hypertensive $[\mathrm{n}=50]$ & 15 & 15 & 26 & 19 \\
\hline Diabetic $[\mathrm{n}=50]$ & 18 & 17 & 37 & 03 \\
\hline
\end{tabular}


Table 7: Common histological findings in different group.

\begin{tabular}{|llll|}
\hline Histological changes in placenta (at term) & Normal cases (\%) & Hypertensive cases (\%) & Diabetic cases (\%) \\
\hline Syncitial knots formation & 18 & 22 & 20 \\
\hline Cytotrophoblastic cellular proliferation & 12 & 10 & 10 \\
\hline Villous fibrinoid deoosition & 14 & 08 & 06 \\
\hline Villous fibrinoid necrosis & 04 & 04 & 04 \\
\hline Stromal fibrosis & 04 & 06 & 04 \\
\hline Thickening of basement membrane & 06 & 10 & 08 \\
\hline Calcification of villi & 06 & 12 & 12 \\
\hline Hyalinization of villi & 08 & 14 & 14 \\
\hline Villous solidification & 04 & 08 & 12 \\
\hline Hofbauer cells & - & - & 02 \\
\hline Endothelial proliferation & & 06 & 08 \\
\hline
\end{tabular}

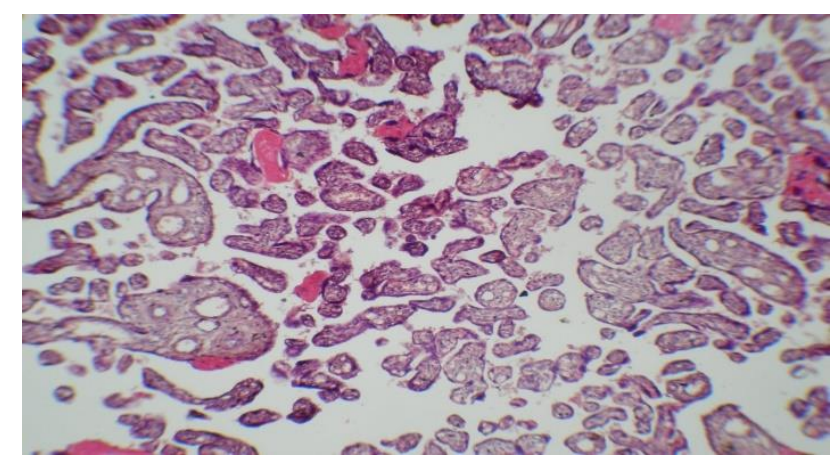

Figure 1: Normal chorionic villi in uncomplicated pregnancy.

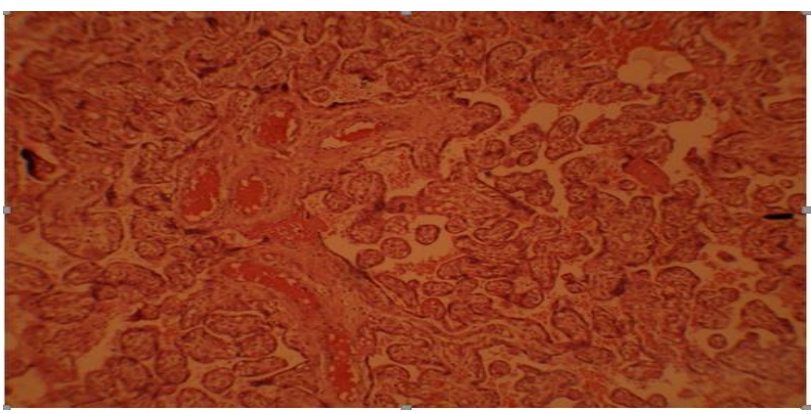

Figure 2: Cytotrophoblastic cellular proliferation in placenta of normal pregnancy

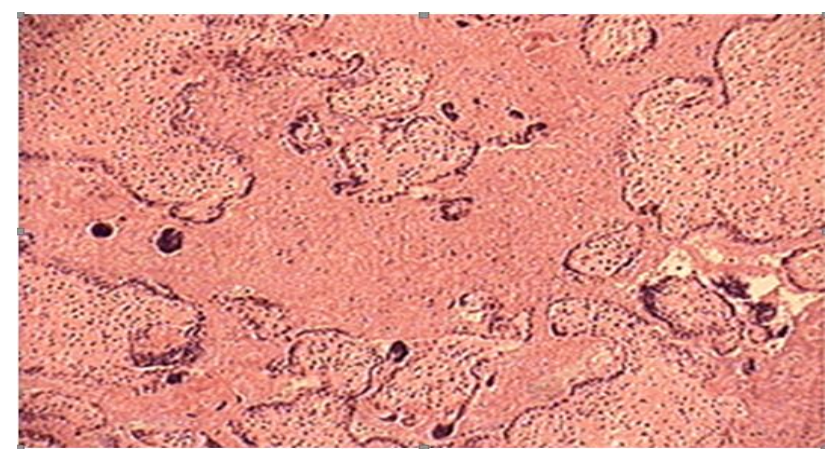

Figure 3: Placental infarction in PIH.

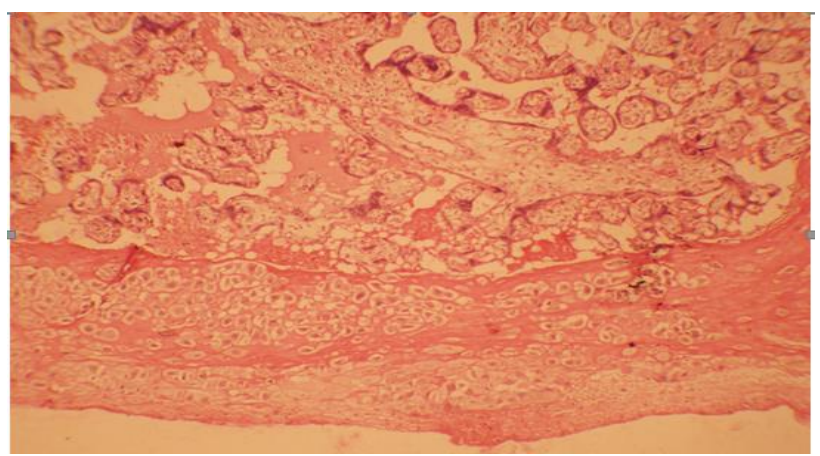

Figure 4: Thickening of basement membrane in placenta of PIH.

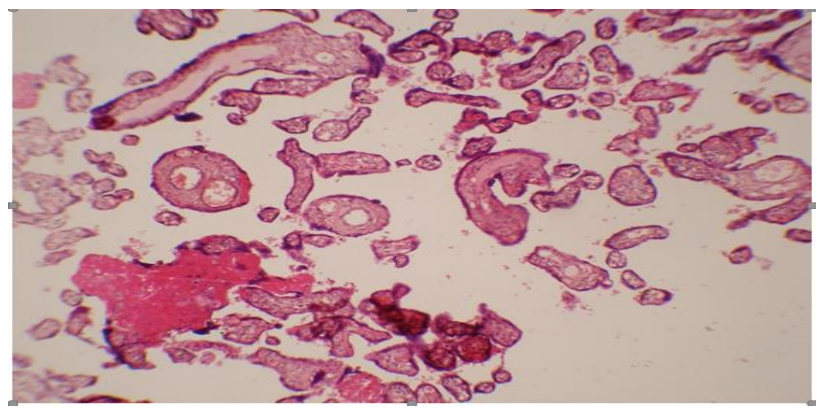

Figure 5: Syncitial knots and villous fibrinoid necrosis -pregnancy in placenta of PIH, H and E x 100

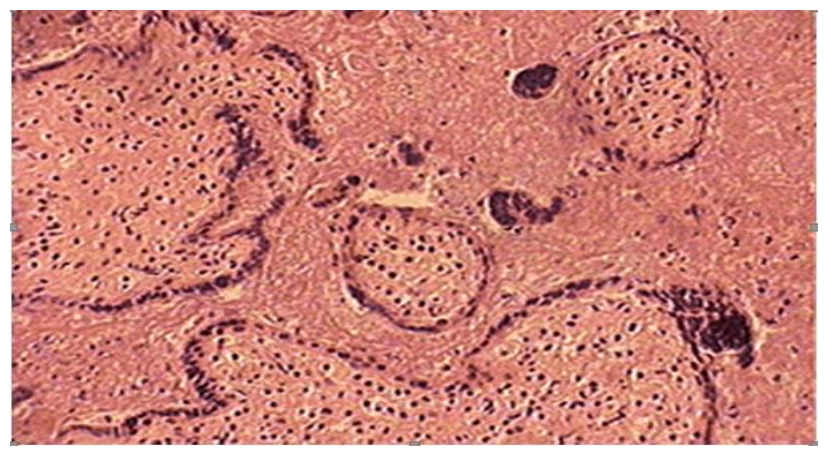

Figure 6: Placental infarction in a case of gestational diabetes. 


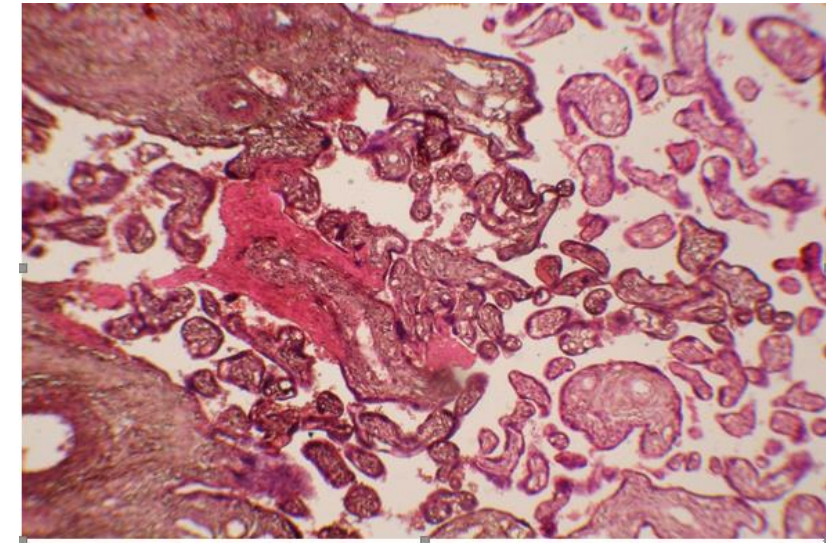

Figure 7: Villous solidification with fibrinoid necrosis in a diabetic placenta, $H$ and $E \times 100$. The important microscopic findings are depicted in figure 7 of diabetic placenta showed increased syncytial knots, fibrinoid necrosis, decreased VSM, and chorangiosis.

\section{DISCUSSION}

The present study was carried out in the department of anatomy as well as in the department of obstetrics and gynecology, MGM Medical College and LSK Hospital over a period of one year (from January 2012 to December 2012). Subjects of this study were selected at random from mothers attending antenatal clinic and also coming for delivery at the department of obstetrics and gynecology. For the purpose of this research works 150 cases of placentae were collected from the labour room and operation theatre as well. Out of these specimens, 50 were collected from normal uncomplicated pregnancy cases, 50 from cases complicated by hypertension and remaining 50 cases were complicated by gestational diabetes mellitus.

It is found that the mothers included in present study were from various age groups, of which the youngest mother was 19 years old and the oldest was 38 years old. For present study purpose, they were broadly classified into three age groups. In the 19-24 years age group there were 45 mothers (30\% of cases). In 25-30 years age group there were 70 mothers $(46.66 \%$ of cases) and in 31 -38 years age group there were 35 mothers $(23.33 \%$ of cases). So, we find that maximum number of cases between 25-30 years age groups mother, which indicates number cases coming for delivery in the hospital in these age groups.

It was shown that average gestational age at the time of delivery was 38.4 weeks in case of normal uncomplicated pregnancy, 36.1 weeks in case of hypertensive mothers and 37 weeks in case of diabetic mothers group. This indicates that normal mothers were delivered closer to term than hypertensive and diabetic mothers.

A study by Ahmed suggests that despite similarities in placental abnormalities, differences in placental pathology may reflect differences in pathophysiology among different types of diabetes. These changes were absent in normal placenta. ${ }^{9}$ Low oxygen tension is physiological for organogenesis and is a key regulator of cellular events in early trophoblast differentiation.

We came to know the perinatal outcome in different groups of pregnancy cases. Here we studied 150 cases in all. In normal case groups out of 50 babies 45 were born in term and 05 were born in preterm. In hypertensive cases, out of 50 cases 45 were born in term, 03 were born in preterm and 03 were still born all were preterm. In diabetic cases, out of 50 cases 40 were born in term, 06 were born in preterm and 04 were stillborn (01 term, 03 preterm).

Mirchandani et al, Masodkar et al and Avasthi et al observed $12 \%, 11.9 \%$ and $12.5 \%$ still births associated with PIH. ${ }^{10-12}$ In present study, IUDs were noted in PIH cases (Table 5). Placental inadequacy and altered placental function may result from primary pathological alterations in the mother, fetus or the placenta ultimately leading to intrauterine growth retardation and IUDs. ${ }^{13}$

Woods and Malan studied 940 placentae and found no correlation between the birth weight and site of cord insertion. $^{14}$ But Rath showed statistical significant between marginal attached of cord and low birth weight. From table 7 we find that the average numbers of cotyledons were 16 in the normal groups, 15 in hypertensive groups and 18 in diabetic groups. Infracted region was 3 in normal groups, 15 in hypertensive groups and 17 in diabetic groups. Area of calcified region was 5 in normal cases, 26 in hypertensive cases and 37 in diabetic cases. Presence of hemorrhage was 3 in normal groups, 19 in hypertensive groups and 03 in diabetic groups.

From table 7 we find the common histological findings which are more or less similar as observed by H Fox. ${ }^{15}$ Syncitial knots were found $14 \%$ in normal, $22 \%$ in hypertensive and $20 \%$ in diabetic cases. Cytotrophoblastic cellular proliferation was found $12 \%$ in normal $10 \%$ in hypertensive and $10 \%$ in diabetic groups. Villous fibrinoid deposition was found $14 \%$ in normal, $08 \%$ in hypertensive and $06 \%$ in diabetic groups. Villous fibrinoid necrosis was found $04 \%$ in normal, $04 \%$ in hypertensive and $4 \%$ in diabetic groups. Villous solidification was found in $4 \%$ in normal, $8 \%$ in hypertensive and $12 \%$ in diabetic cases. Stromal fibrosis was found $4 \%$ in normal, $6 \%$ in hypertensive and $4 \%$ in diabetic cases. Thickening of basement was found $6 \%$ in normal, $10 \%$ in hypertensive and $8 \%$ in diabetic cases. Calcification of villi was found $6 \%$ in normal, $12 \%$ in hypertensive and $14 \%$ in diabetic cases. Hyalinization of villi was found $8 \%$ in normal, $14 \%$ in hypertensive and $14 \%$ in diabetic cases. Endothelial proliferation was found $6 \%$ in hypertensive and $8 \%$ in diabetic cases. Hofbauer cells were found in $4 \%$ of diabetic cases. Histologically, the placentae from pregnancy complicated 
with GDM showed increased incidence of syncitial knots, cytotrophoblastic cell proliferation, and calcification of villi, fibrinoid necrosis, hyalinisation, basement membrane thickening and thickening of the wall of stem arteries. Also, we have seen Hofbauer cells in these placentae. These findings corroborate those of Fox and Perrin Eugene. Daskalakis et al. noted that the presence of degenerative lesions such as fibrinoid necrosis and vascular hyperplasia (chorangiosis) was apparent mainly in the diabetes group. ${ }^{15-18}$

Syncytial knots are focal aggregation or clumping of syncytial nuclei on the surface of a tertiary placental villous, forming a multinucleated protrusion from the villous face of a tertiary placental villous, forming a multinucleated protrusion from the villous surface. These are small collections of structureless, homogeneous, and eosinophilic material within the villous. ${ }^{6}$ Rath in 1994 stated that in hypertension arrangement of the intracotyledonous vasculature is altered; resulting in low birth weight of the babies. ${ }^{19}$

A significant increase in syncytial knot formation in placental villi indicates the disturbance in the hormonal factors, which may probably lead to altered blood flow. According to Robertson, the cause of reduction in blood flow is due to vasculopathies of spiral arteries, which in turn causes reduction in the weight of placenta. It has been recorded that maternal utero-placental blood flow is decreased in preeclampsia because of maternal vasospasm. Reduced maternal utero-placental blood flow indirectly leads to constriction of fetal stem arteries. ${ }^{20}$ Study by Salmani D et al, the histology revealed various structural changes such as significant number of syncytial knots, areas of fibrinoid necrosis, areas of medial coat proliferation of medium sized blood vessels, areas of calcification, and areas of hyalinization (Figure 3, 4, 5, 7). ${ }^{21}$

A significant increase in syncytial knot formation in placental villi indicates the disturbance in the hormonal factors, which may probably lead to altered morphometry of placenta resulting in PIH in the mother and to low birth weight babies. Microscopic findings of localized fibrinoid necrosis, medial coat proliferation of arteries, and hyalinization depict the mosaicism of placenta and probably the aftermath of hypertension. ${ }^{22,23}$ Again the mosaicism of the placenta probably leads to placental insufficiency and ultimately to fetal growth retardation, thus creating a vicious cycle. ${ }^{24}$

On histological observation of placentae, evidence of cytotrophoblastic cellular hyperplasia and patchy necrosis of the villous syncytiotrophoblastic cells are obviousin the study group in comparison to the control group. This is also very much in accordance with the previous studies conducted by Jones and Fox. ${ }^{25}$ Microscopic findings of localised fibrinoid necrosis, endothelial proliferation of arteries and hyalinisation depict the mosaicism of placenta and probably the aftermath of hypertension Teasdale and Udainia et al. ${ }^{22,1}$

Funding: No funding sources

Conflict of interest: None declared

Ethical approval: The study was approved by the Institutional Ethics Committee

\section{REFERENCES}

1. Udainia A, Jain ML. Morphological Study of placenta in pregnancy induced hypertension with its clinical relevance. J Anat Soc India. 2001;50(1):247.

2. Ranga SS. M.K, Adaline Thangam TF, Vasantha Mallika MC, Indira MV. Morphological and histological variations of human placenta in hypertensive disorders of pregnancy. Int J Anat Res. 2017;5(1):3591-8.

3. Redman CW. Stress responses and pre-eclampsia. Pregnancy Hypertens. 2013;3(2):57.

4. Brosens I, Robertson WB, Dixon HG. Fetal growth retardation and the vasculature of the placental bed. Br J Obstet Gynaecol. 1977;84:656-64.

5. Grannum PA, Berkowitz RL, Hobbins JC. The ultrasonic change in the maturing placenta and their relation to fetal pulmonary maturity. AMJ Obstet Gynecol. 1979;133(8):915-22.

6. Augustine G, Pulikkathodi M, Renjith S, Jithesh TK. A study of placental histological changes in gestational diabetes mellitus on account of fetal hypoxia. Int J Med Sci Public Health 2016;5:245760.

7. Ahmed TME. Effect of gestational diabetes on gross morphology, histology and histochemistry of human placenta. Endocrinol Metab Syndr. 2016;5(1):227.

8. Silverman BL, Rizzo TA, Cho NH, Metzger BE. Long-term effects of the intrauterine environment: the Northwestern University Diabetes in Pregnancy Center. Diabetes Care. 1998;21(2):B142-9.

9. Ahmed TME. Effect of gestational diabetes on gross morphology, histology and histochemistry of human placenta. Endocrinol Metab Syndr. 2016;5(1):227.

10. Mirchandani JJ, Bazaz Malik G, Chitra S. Correlation of foetal outcome with some pathological changes of placenta. J Obstet Gynaecol India. 1979; 29:1131-8.

11. Masodkar AR, Kalamkar LR, Patki PS. Histopathology of placenta and its correlation with foetal outcome. J Obstet Gynaecol India. 1985;35: 294-300.

12. Avasthi K, Micha U. Histopathology of placenta and its correlation with foetal outcome. J Obst Gynae India. 1991;41(3):317-28.

13. Mehendale SS, Lele V, Godbole PV. Placental histopathology with IUGR. J Obstet Gynecol India. 1988;138:406-9.

14. Woods DL, Malan AF. The site of umbilical cord insertion and birth weight. British J Obstet Gynecol. 1978;85:332-3. 
15. Fox H. The morphological basis of placental insufficiency. J Obstet Gynaecol India. 1975;25:44150 .

16. Perrin Eugene VDK. Pathology of Placenta. Churchill Livingstone, New York. 1984;77.

17. Daskalakis G, Marinopoulos S, Krielesi V. Placental pathology in women with gestational diabetes. Acta Obstet. Gynecol. Scand. 2008;87:403-7.

18. Saha S, Biswas S, Mitra D, Adhikari A, Saha C. Histologic and morphometric study of human placenta in gestational diabetes mellitus. Italian $\mathbf{J}$ Anat Embryol. 2014;119(1):1-9.

19. Rath G, Garg K, Anand C, Kawle M. Vascular pattern of human placenta in complicated pregnancy,a corrosive cast study. Ann Nat Acad Med Sci. (Ind) 1994;30:17-22.

20. Boyd PA, Scott A. Quantitative structural studies on human placenta associated with preeclampsia essential hypertension and intrauterine growth retardation. Br J Obstet Gynaecol. 1985;92:714-21.

21. Salmani D, Purushothaman S, Somashekara SC, Gnanagurudasan E, Sumangaladevi K, Harikishan R, et al. Study of structural changes in placenta in pregnancy-induced hypertension. J Natural Sci Biol Med. 2014;5(2):352-5.

22. Teasdale F. Gestational changes in functional structure of the human placenta in relation to foetal growth. Am J Obstet. 1980;137:560-2.

23. Chakravorthy AP. Foetal and placental weight changes on normal pregnancy and pre-eclampsia. J Obstet Gynaecol Br Commonw. 1967;74:247-53.

24. Zacutti A, Borruto F, Bottacci G, Giannoni ML, Manzin A, Pallini M, et al. Umbilical blood flow and placental pathology. Clin Exp Obstet Gynaecol. 1992;19:63-9.

25. Jones CJ, Fox H. An ultrastructural and ultrahistochemical study of the human placenta in maternal pre-eclampsia. Placenta. 1980;1(1):61-76.

Cite this article as: Karmakar MK, Kar S, Kumar SM, Chattopadhyay SK, Vaid LK, Sen S. A study of histological changes of human placenta in rural population of eastern India. Int J Reprod Contracept Obstet Gynecol 2018;7:3280-7. 